\title{
Entre dizeres e fazeres: evidências de um processo de formação continuada
}

\author{
Between sayings and doings: evidences of a process of \\ continuous formation
}

\section{Entre decir y hacer: evidencias de un proceso de formación continua}

\author{
Luciene Paula Machado Pereira ${ }^{1}$
}

\begin{abstract}
RESUMO: O artigo se propõe a apresentar uma análise comparativa entre concepções expressas acerca de língua, texto e trabalho com língua materna e em parte do planejamento pedagógico de professores atuantes nos anos finais do Ensino Fundamental, participantes de curso de formação continuada. Concebendo o planejamento pedagógico como ação de linguagem constitutiva do agir profissional do docente, a relação entre teoria e prática ou entre as concepções internalizadas e as situações didáticas representadas deixa entrever a constituição identitária do professor expressa pelo seu agir. Evidenciamos o distanciamento de uma prática pedagógica em relação à concepção da língua enquanto realização discursiva, o que se reflete na presença do texto em sala de aula direcionado para a efetivação de um trabalho focado em aspectos estruturais, descontextualizado.
\end{abstract}

PALAVRAS-CHAVE: Planejamento pedagógico. Ação de linguagem. Trabalho docente.

ABSTRACT: This article proposes to present a comparative analysis between express concepts about language, text and work with native language and part of the pedagogical planning for active teachers of the final years of Elementary School, participants of a continuing education course. Conceiving pedagogical planning as a language action constitutive of the professional action of the teacher, the relation between theory and practice or between the internalized conceptions and the didactic situations represented allows us to glimpse the identity constitution of the teacher expressed by their action. We show the distance of a pedagogical practice in relation to the conception of the language as a discursive realization, which is reflected in the

${ }^{1}$ Doutoranda no Programa de Pós-Graduação em Estudos da Linguagem da Universidade Estadual de Londrina (UEL), área de concentração em Linguagem e Educação. Professora na Universidade Federal de Mato Grosso do Sul (UFMS), atuando com disciplinas de Língua Portuguesa, Prática de Ensino e Estágio de Língua Portuguesa. E-mail: lucyenepaula@gmail.com 
presence of text in the classroom directed to the accomplishment of a work focused on structural aspects, decontextualized.

KEYWORDS: Pedagogical planning. Language action. Teaching work.

RESUMEN: El artículo se propone presentar un análisis comparativo entre concepciones expresas acerca de lengua, texto y trabajo con lengua materna y en parte de la planificación pedagógica de profesores actuantes en los años finales de la Enseñanza Fundamental, participantes de curso de formación continua. La relación entre teoría y práctica 0 entre las concepciones internalizadas y las situaciones didácticas representadas deja entrever la constitución identitaria del profesor expresada por su actuar, concibiendo la planificación pedagógica como acción de lenguaje constitutivo del actuar profesional del docente. Se evidenció el distanciamiento de una práctica pedagógica en relación a la concepción de la lengua como realización discursiva, lo que se refleja en la presencia del texto en el aula dirigido a la efectividad de un trabajo enfocado en aspectos estructurales, descontextualizado.

PALABRAS CLAVE: Planificación pedagógica. Acción de lenguaje. Trabajo docente.

\section{Considerações Iniciais}

O trabalho docente significativo preconiza a ação efetiva e consciente dos sujeitos envolvidos no processo: o aluno como sujeito ativo na construção de seu conhecimento e o professor como mediador desse processo a partir dos objetivos traçados, dos conteúdos organizados e das situações didáticas pensadas. Quando esses sujeitos se alijam de seus papéis, a atividade educacional não se realiza, já que não existe a aquisição de conhecimentos e a transformação dos sujeitos; correndo-se o risco de perpetuar o ciclo em que o aluno não vivencia ou vivencia pouco atividades que o levem a refletir sobre o uso linguístico e a instaurar-se como sujeito do seu dizer, tendo experiências comunicativas que o levem a aprimorar o seu desempenho discursivo em diversas situações. E, nesse contexto, o professor apenas reproduz o que está posto como objetivo de trabalho (seja no livro didático, seja nos referenciais curriculares) sem instaurarse como mediador, apenas seguindo um roteiro pré-estabelecido, focado no conteúdo a ser trabalhado, desvinculando a organização do seu agir das necessidades postas pelos seus alunos. 
Especificamente em relação à língua portuguesa enquanto língua materna, uma prática significativa necessita, de um lado, de um professor consciente do uso que faz de sua língua nas mais diversas práticas sociais e, do outro, do domínio de saberes dos mecanismos que possibilitam à língua a construção de sentidos nos mais diversos cenários discursivos. Ou seja, para ensinar língua e ajudar um indivíduo a desenvolver plenamente sua competência sociocomunicativa - objetivo maior do trabalho com a língua materna em sala de aula (BRASIL, 1998, p. 19), conforme corroboram os documentos institucionais e as pesquisas acadêmicas - também o professor tem que ser competente sociocomunicativamente. Refletir sobre a constituição do agir docente pode contribuir para o entendimento da profissionalidade do professor e, consequentemente, colaborar para o desenvolvimento de uma prática de ensino de língua mais significativa.

Nas próximas seções, discutiremos o planejamento pedagógico como ação de linguagem e o trabalho docente, segundo os preceitos do Interacionismo Sociodiscursivo - ISD; explicitaremos o contexto da análise, apresentando as concepções oficiais, expressas pela Base Nacional Comum Curricular - BNCC - e os dados dos professores sujeitos da análise e, por fim, apresentaremos as reflexões que os dados nos permitem concluir.

\section{O planejamento pedagógico como ação de linguagem}

Como ação de linguagem, o planejamento pedagógico poderá possibilitar a compreensão de como o sujeito desenvolve a sua identidade enquanto professor ao executar as ações inerentes ao seu trabalho, na medida em que a alienação profissional, consequência de tantos fatores, mostra-se quando o professor se abstém de refletir sobre a prática realizada contrapondo-a ao previamente planejado; quando não traça objetivos pertinentes ao grupo de alunos reais com o qual trabalha, mas reproduz os já existentes nos manuais; quando pensa situações didáticas que não consideram a língua como atividade 
discursiva, interacional, alijando essas atividades dos objetivos pensados e/ou inviabilizando, pelo seu trabalho, o desenvolvimento da competência sociocomunicativa de seus alunos. Estando a ação de linguagem do sujeito orientada por seus esquemas de utilização do artefato simbólico, em eventos de interação (MATENCIO, 2007, p. 56), o planejamento pedagógico realiza-se como etapa anterior à execução da aula e também como etapa posterior à atividade realizada, constituindo-se, ademais de um instrumento psicológico para a ação docente, como um instrumento de mediação entre a ação realizada no espaço da sala de aula e a reflexão/assimilação dos resultados dessa ação e a sua posterior assimilação e apreensão pelo docente, modificando e/ou ampliando, dessa forma, a sua constituição profissional.

Concebendo-se o trabalho docente como elemento importante da formação cidadã do indivíduo/aluno, cuja construção também se institui no acesso aos conhecimentos formais e, no que tange ao ensino de língua materna, aos conhecimentos linguísticos e discursivos necessários à apreensão dos mais diversos textos que circulam socialmente, reconhece-se que esse trabalho não se realiza satisfatoriamente. Conforme atestam diversas provas, nacionais e internacionais (como PISA, ENEM, Prova Brasil), e o nosso próprio contato com salas de aula da Educação Básica, por meio de projetos, PIBID, estágios, os estudantes demonstram um desempenho insatisfatório em relação às competências esperadas, como baixa compreensão leitora e inabilidade em articular ideias organizando-as em uma unidade de sentido, ou seja, em construir textos plenos de intencionalidade e cumprindo sua função sociocomunicativa. Um trabalho pedagógico distanciado de sua função cidadã conceberá a língua desprovida de seu valor discursivo, alienada do uso que a torna viva e, dessa forma, ensinar língua portuguesa a falantes nativos dessa língua seria apenas trabalhar um conteúdo formal, com suas regras e exceções, a ser apreendido porque o sistema escolar assim o exige.

No atual cenário brasileiro, em que se somam aos já clássicos Parâmetros Curriculares Nacionais (PCN) a Base Nacional Comum Curricular (BNCC), 
homologada em 2017, reforça-se a necessidade de "processos permanentes de formação docente que possibilitem contínuo aperfeiçoamento dos processos de ensino e aprendizagem." (BRASIL, 2017, p. 17). A formação continuada é, pois, de extrema importância para a efetiva implementação desse ensino de língua portuguesa que se quer significativo e que trabalha em uma perspectiva enunciativo-discursiva.

\section{0 trabalho docente}

O contexto do trabalho do professor é pleno de pressupostos sobre a imagem e as capacidades que os indivíduos atuantes nessa profissão devem ter. Espera-se que sejam sujeitos íntimos com o conteúdo base da licenciatura escolhida. Especificamente em relação à língua portuguesa, que sejam sujeitos leitores de diversos textos, conhecedores de grandes obras literárias, sensíveis à apreensão dos mecanismos linguísticos forjados para a expressividade textual, aptos à produção eficiente de diversos textos em diversas situações, principalmente naquelas de uso formal e com finalidades didáticas. No agir profissional do professor, esses pressupostos se concretizam na aquisição de conhecimentos teóricos, de conhecimentos didáticos e a um comprometimento com a condição educacional e sua peculiaridade de instituir-se na base de um duplo movimento: o ensino e a aprendizagem.

Ao professor pesa a competência necessária ao seu complexo agir profissional. Por essa competência espera-se o êxito em organizar a sua prática de maneira significativa, ou seja, gerenciar as relações/os acontecimentos da sala de aula estabelecendo-se como mediador no processo de construção de conhecimentos do seu aluno, por meio da organização e aplicação de situações didáticas pertinentes a um entendimento do valor discursivo da língua e de suas possibilidades de realização. A plena realização da competência está atrelada ao funcionamento dos recursos mobilizados no indivíduo, notadamente os conhecimentos, métodos, comportamentos que assumem a condição de 
competência quando o sujeito está em seu processo de agir (BRONCKART, 2006, p. 197). Considerando a prática docente em sala de aula e refletindo sobre o "eterno" período de transição vivenciado em relação à passagem de um ensino tradicional de língua materna para um ensino condizente com os preceitos sociointeracionistas, pode-se questionar que recursos faltam aos professores ou por que o processo de mobilização dos recursos não é eficaz o suficiente para garantir a elaboração e execução de atividades significativas.

Faz-se necessário reconhecer, conforme ratifica Bronckart (2006, p. 198), que as ações constituintes do agir não podem ser explicadas plenamente apenas pelos recursos/competências do agente, uma vez que há redes de restrições sociais e materiais que interferem no percurso do agir, inclusive impedindo a realização do planejado. No entanto, embora o percurso da sala de aula seja regulado por interações de diversas ordens, a etapa inicial do percurso do agir do profissional professor, concretizada na elaboração de seu planejamento pedagógico, demonstra os recursos mobilizados nesse sujeito, que podem caracterizá-lo ou não como ator, dotado de capacidades, motivações e intenções. A autonomia/capacidade de o professor gerenciar o seu projeto de ensino pode ser uma das marcas mais importantes de sua profissionalidade, como salienta Guimarães (2014, p. 614), e a presença de um discurso idealizado/modelo, encontrado nos textos oficiais e também em textos produzidos pela Academia acerca do trabalho com a língua materna, e que deve ser seguido para a execução de uma prática satisfatória, pode ser apropriado pelo professor sem, de fato, haver a mobilização de capacidades e motivações para a sua concretização. Sendo os recursos construídos na ação e, consequentemente, a própria competência, como a mobilização dos recursos no percurso do agir, ser uma propriedade constitutiva da ação (BRONCKART, 2006, p. 199-200), a capacidade profissional, no sentido da instauração da identidade de agir como professor, constrói-se continuamente, mesmo quando não está em vivência de um agir em contexto profissional e, estando-se nesse contexto, mostra-se na ação inicial do planejamento, guia/roteiro para o que será realizado em sala de 
aula. Assim, o planejamento pedagógico é material para a apreensão dos recursos e competências constitutivos do profissional professor.

\section{O contexto da formação continuada}

O curso de formação continuada por nós coordenado, intitulado "Curso de formação: a Sequência Didática e o ensino de língua materna", trabalhou com professores de Língua Portuguesa atuantes nos anos finais do Ensino Fundamental em escolas integrais, urbanas e rurais, da rede municipal de ensino de Corumbá, MS². Em sua primeira edição, no ano de 2016, o objetivo maior do curso era a apropriação da metodologia da Sequência Didática, tal como concebida pela vertente didática do Interacionismo Sociodiscursivo Schneuwly e Dolz, entre outros, uma vez que se estabelece como uma possibilidade profícua de organização didática para um trabalho significativo com a língua materna (NASCIMENTO; GONÇALVES, 2018). ${ }^{3}$

A identificação das percepções didáticas de informações e conceitos teóricos tais como os professores deles se apropriam e o entendimento de como essa apropriação culmina em determinadas escolhas metodológicas podem, por consequência, contribuir para que a qualidade do trabalho docente se eleve, na

\footnotetext{
${ }^{2} \mathrm{O}$ referido curso de formação continuada foi realizado em parceria com a Secretaria Municipal de Educação de Corumbá-MS e coordenado pela autora em colaboração com a Professora Dra. Regiane Coelho Pereira Reis, ambas docentes dos cursos de Letras da UFMS. O curso de formação também teve a colaboração de discentes do Curso de Letras, em sua maior parte também bolsistas de iniciação à docência do PIBID, coordenado pela Professora Regiane Reis com a colaboração da autora. O curso, realizado como projeto de extensão, teve uma proposta replicada em 2017. Um primeiro artigo analisando os dados obtidos com os questionários inicial e final do curso em 2016 foi publicado no volume temático sobre o ISD na Revista Veredas (PEREIRA, 2017).

3 A Sequência Didática é definida por Dolz, Noverraz e Schneuwly (2004, p. 82) como "um conjunto de atividades escolares organizadas, de maneira sistemática, em torno de um gênero textual oral ou escrito". No curso de formação que serve de base para a constituição de nosso corpus neste artigo, os professores elaboraram um planejamento para dez $\mathrm{h} / \mathrm{a}$, o que equivale a cerca de duas semanas de trabalho. Este fator temporal limitou a completude da abordagem com a SD que, embora procurasse apresentar o esquema padrão estabelecido, teve limitações marcantes. O objetivo maior na ocasião era que os professores tivessem acesso a essa possibilidade didática e se apropriassem de uma forma de organizar as aulas em torno de um gênero textual e de sua apropriação pelos alunos.
}

Entretextos, Londrina, v. 19, n. 1, p. 331- 346 Dossiê Temático/ 2019 
medida em que o profissional, ao entender as razões de suas práticas e escolhas, constrói, pela tomada consciente e reflexiva sobre o seu agir, a sua identidade profissional e o sentido de sua atuação em sala de aula.

\section{Os dizeres: as concepções teóricas em curso}

Uma perspectiva de ensino de Língua Portuguesa que se coloca como significativa na medida em que aprimore/desenvolva a competência sociodiscursiva dos alunos concebe a língua como atividade social, manifesta no uso em práticas linguageiras e sociais. Nessa perspectiva sociointeracionista, a língua concebida como lugar de interação social acarreta em uma compreensão de texto e leitura ancorada no funcionamento interacional da língua. $O$ texto visto como unidade significativa de comunicação e a leitura como processo de produção de sentido instaurado na relação interativa leitor-texto-autor são concepções que se pretendam que estejam internalizadas pelo docente para atingir o objetivo maior de contribuir para o desenvolvimento da competência sociodiscursiva dos seus alunos. Nas próximas seções, apresentaremos como esses conceitos são trazidos no mais recente documento norteador do ensino de língua materna no Brasil, a BNCC, e como os professores do curso de formação já referido mostram o seu posicionamento acerca deles, por meio de sua expressão em questionários e no planejamento por eles realizado.

\section{A BNCC}

A Base Nacional Comum Curricular referente às etapas da Educação Infantil e do Ensino Fundamental - anos iniciais e anos finais - constitui-se como documento norteador à elaboração dos currículos municipais e estaduais. Ancorada nos objetivos que cada etapa de educação deve alcançar, a BNCC se pauta pela definição de competência como: 
[...] a mobilização de conhecimentos (conceitos e procedimentos), habilidades (práticas, cognitivas e socioemocionais), atitudes e valores para resolver demandas complexas da vida cotidiana, do pleno exercício da cidadania e do mundo do trabalho (BRASIL, 2017, p. 8).

Ancorada em uma concepção enunciativo-discursiva de língua(gem), a BNCC segue considerando o texto como unidade básica de ensino para o trabalho com as práticas de leitura e produção, de modo que se considere que apenas o trabalho contextualizado com a língua possibilita a ampliação dos letramentos dos estudantes (BRASIL, 2017, p. 65). Nessa perspectiva de como deve ser 0 trabalho ideal com a língua materna/portuguesa, as práticas de linguagem oralidade, leitura/escuta, análise linguística/semiótica e produção de textos - se inserem como eixos de integração para o trabalho com os conteúdos em língua portuguesa. A leitura se caracteriza pela interação ativa do leitor com os textos, considerada também nas possibilidades dos textos multissemióticos, assim como a produção textual se insere na relação ativa do sujeito aluno com a linguagem na assunção de seu papel como autor de seu dizer, nas mais diversas práticas sociais que vivencia. Nessa perspectiva, "a Análise Linguística/Semiótica envolve os procedimentos e estratégias (meta)cognitivas de análise e avaliação consciente, durante os processos de leitura e de produção de textos" (BRASIL, 2017, p. 78), constituindo-se, pois, como "ferramenta" necessária à plena realização da leitura e produção de textos, com o objetivo de contribuir para a realização das atividades linguísticas/discursivas (MENDONÇA, 2006, p. 208). Como afirma a BNCC,

Os conhecimentos sobre a língua, as demais semioses e a normapadrão não devem ser tomados como uma lista de conteúdos dissociados das práticas de linguagem, mas como propiciadores de reflexão a respeito do funcionamento da língua no contexto dessas práticas. A seleção de habilidades na BNCC está relacionada com aqueles conhecimentos fundamentais para que o estudante possa apropriar-se do sistema linguístico que organiza o português brasileiro (BRASIL, 2017, p. 137). 
A BNCC salienta, pois, a integração entre os eixos de ensino/práticas de linguagem, de modo que se evidencia a necessidade de, na escola, construir-se situações didáticas que permitam ao aluno vivenciar diversas práticas de linguagem, usando a língua ao mesmo tempo em que desenvolve o seu repertório, de modo a aprimorar-se como usuário dessa língua, em um processo contínuo e sistematizado, tal como deve ser o processo escolar.

\section{- Os professores}

Os dados trazidos para a análise são, primeiramente, respostas de três professores de Língua Portuguesa atuantes no Ensino Fundamental II na rede municipal de ensino de Corumbá-MS, participantes, como já referido, do curso de formação continuada intitulado "Curso de formação: a Sequência Didática e o ensino de língua materna", no período de outubro a dezembro de 2016, em conjunto com partes do planejamento pedagógico desses docentes, de modo a verificar a relação do que foi expresso no questionário inicial com o que consta no planejamento. Assim, consideraremos como corpus para análise as respostas a quatro perguntas contidas em questionário inicial respondido pelos professores: 1) Qual é a concepção de língua adotada por você?; 2) O que são práticas de linguagem?; 3) O que é texto?; e 4) O que é ensinar Língua Portuguesa?4. Esses questionamentos, para fins de decodificação e análise serão apresentados do seguinte modo: Q1, Q2, Q3 e Q4; e os três docentes serão codificados como: D1, D2 e D3.

Vejamos como cada professor, sujeito da análise, se posiciona acerca das concepções de língua, texto e ensino ${ }^{5}$ :

\footnotetext{
${ }^{4}$ As questões presentes no questionário inicial foram: 1) Qual é a concepção de língua adotada por você?; 2) Qual é o objetivo do trabalho com a língua materna?; 3) O que são práticas de linguagem?; 4) $O$ que é texto?; 5) Por que e como trabalhar o texto?; 6) Como corrigir o texto? e 7) $O$ que é ensinar Língua Portuguesa?.

${ }^{5}$ Adotamos a transcrição grafemática dos discursos escritos dos sujeitos da pesquisa, ou seja, discurso retratado na íntegra, sem alterações de cunho indicativo.

Entretextos, Londrina, v. 19, n. 1, p. 331- 346 Dossiê Temático/ 2019 
D1: "A comunicação entre o ser humano" (Q1).

"Prática de linguagem, os códigos, sinais e meios metodológicos" (Q2).

"É a formação de palavras que em conjunto forma-se texto, de acordo com o tema, obtendo sentido" (Q3).

"Ensinar não, compreender a língua portuguesa e todos os seus aspectos sociais e contextualização. Fazendo a junção entre a forma coloquial a forma padrão, sem desconsiderar o certo ou erradd" (Q4).

O sujeito D1 apresenta uma visão de língua enquanto código, instrumento/meio de comunicação, distante, pois, de uma visão sociointeracionista de língua(gem), como se evidencia pelo entendimento demonstrado sobre o que são práticas de linguagem (Q2). O sujeito D2 colocou como descrição das etapas de seu planejamento:

- Dia 31/10 (2h/a) apresentação do tema a turma, carta de leitor, aplicando textos no data show, leitura, apresentação estrutural e lista de constatação. Depois, dialogar com a turma sobre o conteúdo abordado, questionando os para que possamos trocar conhecimentos do determinado assunto. Entregar aos alunos revistas, apresentando a carta de leitor que consta no início da revista, no qual cada aluno fara uma leitura da sua carta.

- Dia 01/11 (2h/a) aplicar a atividade parágrafo padrão, com o tema "A tecnologia em suas mãos", nesta atividade os alunos deverão escrever em 10 linhas, introdução, desenvolvimento e conclusão, sendo dado a eles um texto de apoio. Após a produção o professor fara uma breve leitura nos textos dos alunos e entregara para a turma que será formada em duplas, essas duplas farão correção no texto dos colegas e devolverão para o professor.

- Dia 03/11 (1h/a) entregar para os alunos cópias de texto retirado de revista ou jornais, o qual eles deverão produzir de acordo com tema uma carta de leitor.

- Dia 07/11(2h/a) continuação da produção de gênero, sendo entregue ao professor para verificação e correção.

Pela organização apresentada, identifica-se uma ausência de preocupação em considerar o texto enquanto discurso, ação de linguagem inserida em um contexto de produção, conforme se evidencia nas duas primeiras aulas, em que à apresentação inicial dos textos em slides, segue-se a sua "apresentação estrutural" e lista de constatação, evidenciando-se uma prática didática em que o gênero textual é tomado como conteúdo em detrimento das práticas de 
linguagem. Ou seja, um trabalho "conteudista" e "gramatiqueiro" pode persistir ainda que o professor leve o texto para a sala de aula.

O sujeito D2 apresenta as seguintes concepções acerca dos conceitos de língua, práticas de linguagem, texto e sobre o objetivo com o trabalho pedagógico de língua materna:

D2: "Língua é um conjunto de códigos que um determinado grupo utiliza com o intuito de se comunicar" (Q1).

"São as diversas formas que usamos para nos expressarmos. Linguagem verbal ou não verbal" (Q2).

"É um conjunto de palavras que expressam um sentido completo, que passa uma mensagem. O texto pode ser escrito ou oral" (Q3).

"É assumir um desafio; é apresentar ao educando as possibilidades que a Língua Portuguesa nos oferece. Mostrar que muito mais que saber ler e escrever é utilizar a língua pela sua função social' (Q4).

Novamente, evidencia-se uma concepção de língua enquanto código e de texto como correspondendo a um conjunto de palavras, embora haja o entendimento de que o objetivo do trabalho com a língua é que o aluno saiba "utilizar a língua pela sua função social". A seguir, um trecho do planejamento do docente, que especifica a descrição das aulas planejadas:

- 03/11 $\rightarrow$ Retomada do gênero, introduzindo a aula com a apresentação dos vídeos "Almir Sater contando causos com Rolando Boldrin." e "O causo do dia". Em seguida expor a lista de constatações trabalhando as características do gênero, concluindo com a entrega dos textos iniciais explicando a importância da preservação desses textos para atividades de reescrita;

- 04/11 $\rightarrow$ Atividade de reescrita de um texto com repetições desnecessárias para auxiliar o aluno a desenvolver a escrita de maneira adequada;

- 08/11 $\rightarrow$ Correção da atividade de produção inicial, selecionando um dos textos produzidos para análise coletiva. Ressaltando os aspectos da oralidade e da escrita;

- 10/11 $\rightarrow$ Aplicação da dinâmica de contação de história. Nessa dinâmica os alunos se colocarão em dupla, alternadamente enquanto um conta um causo, o outro deverá registrar esse causo escrevendo o que ouviu. Assim trabalharemos a oralidade e a escrita. Após toda a turma terminar o registro, convidar algumas duplas a lerem os textos.

- $11 / 11 \rightarrow$ Convidar os alunos a reescrever o texto inicial, fazendo as 
adequações necessárias de acordo com o estudo feito sobre o gênero relato de causo.

O sujeito D2, embora ressalte a "função social" da língua como destacado anteriormente, trabalha o gênero "relato de causo" fortemente ancorado em uma oposição entre oralidade e escrita, valendo-se de atividades prescritivas, conforme se evidencia na descrição das aulas do dia 04 e 08/11. Nesse sentido, a relação entre a oralidade e a escrita inserida em um relato de causo não é considerada na discursivização do texto, ou seja, não está se considerando o fato de que o gênero oral é retextualizado, mas deve preservar as suas características.

Por fim, o sujeito D3 e a manifestação de suas concepções seguida de trecho do seu planejamento pedagógico:

D3: "Língua (fala) é o meio em que temos para que haja comunicação" (Q1).

"Trabalhar a língua com suas diversas formas, seja linguagem verbal ou não verbal" (Q2).

"Para que exista um texto é necessário que tenha sentido completo, ou seja, que esteja inserido em um contexto. Caso ao contrário serão palavras soltas ou imagens sem sentido, levando em conta também a linguagem verbal e a não verbal' (Q3).

"É mais do que um simples ensinar da língua materna. É ensinar compreender, organizar ideias, questionar, responder. É permitir que haja comunicação de forma clara e objetiva" (Q4).

- 31/10 (1h/a) - Devolutiva da primeira versão do texto produzido no dia 24/10. Entregar os textos aos alunos e a partir destes trabalhar marcas da oralidade, debatendo os itens corrigidos de acordo com as características do gênero proposto tendo como base a lista de constatações. Módulo1.

- 03/11 (02h/a) - Entregar fotocópia do texto "Causo do mineiro" e realizar atividades do módulo 2 em anexo.

- 07/11 (01h/a) - Realizar atividades do módulo 3 em anexo texto "A caveira da tia Juliana" e em seguida cada aluno compartilhará com a turma frases que contenham MAS/MAIS.

- 09/11 (02h/a) - Entregar digitado um texto produzido por um aluno da turma para que os alunos completem as lacunas com as orientações entre parênteses. Atividade do módulo 4 em anexo.

- 10/11(02h/a) - Produção final a partir da ideia da produção inicial. 
O sujeito D3, também ancorado em uma visão de língua enquanto instrumento de comunicação, em que pese a inapropriação de relacionar o não verbal à língua (Q2), visualiza a relação do texto com o contexto, compreendendo a necessidade da completude do sentido e do desenvolvimento do aluno enquanto usuário ativo da língua. Mas, em um curto espaço de tempo, o professor opta por trabalhar exercícios estruturais, como o preenchimento de lacunas nas aulas dos dias 07 e 09/11, em detrimento de aprofundar aspectos discursivos do gênero em questão, tais como as temáticas predominantes e o contexto de produção e uso/recepção, não trabalhando a subjetividade do aluno na prática de leitura do texto, sendo novamente enfatizada a oposição entre oralidade e escrita.

\section{Considerações Finais}

A alienação/mecanização do trabalho docente, considerando-se o planejamento pedagógico como parte fundamental desse trabalho, caracterizase pela reprodução do discurso institucionalizado dos preceitos sociointeracionistas sem efetivamente realizá-los na organização de situações didáticas que propiciem a apreensão dos mecanismos linguageiros pertinentes à eficácia em determinada situação comunicativa.

Instituindo-se como gerenciador da dinâmica da sala de aula, pesquisas sinalizam que o professor, de maneira geral, abstém-se de seu real papel e apenas reproduz conteúdos, alienando-se de suas ações (MAGALHÃES; LIBERALI, 2004), de modo que se evidencia a falta de articulação entre o discurso do professor e a sua prática (NASCIMENTO; GONÇALVES, 2018, p. 10). Primordial para a realização de uma prática significativa é a atuação de um professor consciente e autônomo em relação às escolhas conceituais e didáticas que faz, que se constrói como mediador do processo de ensino e aprendizagem na execução de um planejamento pedagógico possibilitador de uma atuação significativa, porque concebe a língua como atividade social e interativa e 
trabalha o texto na sua constituição de gênero textual, dando primazia aos elementos constitutivos da situação interativa, de maneira que o dizer tenha sentido.

Nota-se, nos cursos de formação continuada por nós coordenados, destinados a professores de Língua Portuguesa atuantes no Ensino Fundamental II de escolas públicas, a falta de domínio de práticas pedagógicas significativas, que permitam a execução de situações didáticas facilitadoras, para o aluno, do desenvolvimento do conhecimento linguístico e discursivo necessário à apreensão dos diversos gêneros textuais, cujo domínio constitui a competência sociocomunicativa do indivíduo/cidadão.

O entendimento de como a profissionalidade do professor se constitui passa pela consideração de sua formação inicial e dos preceitos teóricos que tem internalizado, bem como pela assimilação das possibilidades metodológicas que concretizam um trabalho com a língua em sua concepção discursiva/sociointeracionista, assim como pela postura que tem diante do papel que desempenha, se assume a consciência de sua função social.

\section{Referências}

BRASIL. Ministério da Educação e Cultura. Parâmetros Curriculares Nacionais: terceiro e quarto ciclos do Ensino Fundamental: língua portuguesa. Brasília, DF: MEC/SEF, 1998.

BRASIL. Ministério da Educação. Base Nacional Comum Curricular. Brasília, DF: MEC/SEB, 2017.

BRONCKART, Jean-Paul. As condições de construção dos conhecimentos humanos. In: BRONCKART, Jean-Paul. Atividade de linguagem, discurso e desenvo/vimento humano. São Paulo: Mercado de Letras, 2006. p. 175-202.

DOLZ, Joaquim; NOVERRAZ, Michèle; SCHNEUWLY, Bernard. Sequências didáticas para o oral e a escrita: apresentação de um procedimento. In: DOLZ, Joaquim; SCHNEUWLY, Bernard. Gêneros orais e escritos na escola. São Paulo: Mercado de Letras, 2004. p. 81-108. 
GUIMARÃES, Ana Maria de Mattos. Pelos caminhos do ISD na sala de aula de língua materna. Eutomia, Recife, v. 13, n. 1, p. 604-625, jul. 2014.

MAGALHÃES, Maria Cecília Camargo; LIBERALI, Fernanda Coelho. O interacionismo sociodiscursivo em pesquisa com formação de educadores. Calidoscópio, São Leopoldo, RS, v. 2, n. 02, p. 105-111, jul./dez. 2004.

MATENCIO, Maria de Lourdes Meirelles. Textualização, ação e atividade: reflexões sobre a abordagem do interacionismo sociodiscursivo. In: GUIMARÃES, Ana Maria de Mattos; MACHADO, Anna Rachel; COUTINHO, Antónia. (org.). O interacionismo sociodiscursivo: questões epistemológicas e metodológicas. São Paulo: Mercado de Letras, 2007. p. 51-63.

MENDONÇA, Márcia. Análise Linguística no ensino médio: um novo olhar, um outro objeto. In: MENDONÇA, Márcia; BUNZEN, Clécio. Português no ensino e médio e formação do professor. São Paulo: Parábola Editorial, 2006. p. 199-226. (Série Estratégias de Ensino, v. 2).

NASCIMENTO, Elvira Lopes; GONÇALVES, Adair Vieira. A perspectiva interacionista sociodiscursiva no trabalho educacional. In: CRISTOVÃO, Vera Lúcia Lopes (org.). Gêneros (textuais/discursivos): ensino e educação (inicial e continuada) de professores de línguas. Campinas: Mercado de Letras, 2018. v. 1, p. 26-49.

PEREIRA, Luciene Paula Machado; REIS, Regiane Coelho Pereira. Experiência em formação continuada: andaimes da prática docente. Veredas, Juiz de Fora, v. 21, n. 3, 2017. p. 326-337. 